\title{
Bazı bitkisel uçucu yağların Aphis craccivora (Koch) ve Myzus persicae (Sulzer) (Hemiptera: Aphididae)'ya karşı fumigant etkileri
}

\author{
Fumigant effects of some plant essential oils against Aphis craccivora (Koch) and Myzus \\ persicae (Sulzer) (Hemiptera: Aphididae)
}

\author{
Orhan MÜLAYIM ${ }^{1 *}$ iD Özdemir ALAOĞLU ${ }^{1}$ iD , Hüseyin ÇETIN ${ }^{1}$ iD \\ ${ }^{1}$ Selçuk Üniversitesi Ziraat Fakültesi, Bitki Koruma Bölümü, Konya
}

To cite this article:

Mülayim, O., Alaoğlu, Ö. \& Çetin, H. (2020). Bazı bitkisel uçucu yağların Aphis craccivora (Koch) ve Myzus persicae (Sulzer) (Hemiptera: Aphididae)'ya karşı fumigant etkileri. Harran Tarım ve Gıda Bilimleri Dergisi, 24(2): 195203.

DOI: 10.29050/harranziraat.629353

Address for Correspondence: Orhan MÜLAYIM

e-mail:

omulayim@selcuk.edu.tr

Received Date:

04.10 .2019

Accepted Date:

24.02.2020

(C) Copyright 2018 by Harran University Faculty of Agriculture. Available on-line at www.dergipark.gov.tr/harranziraat
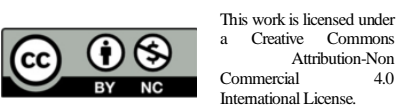

öz

Afitler bitki öz suyu ile beslenen, hızlı çoğalan polifag zararlılar olup, ilaçlara karşı kısa sürede direnç geliştirmektedirler. Bu çalışmada kekik (Origanum onites L.), anason (Pimpinella anisum L.), rezene (Foeniculum vulgare Mill.) ve lavanta (Lavandula angustifolia Mill.) uçucu yağlarının Aphis craccivora Koch ve Myzus persicae Sulzer (Hemiptera: Aphididae) 'nın erginlerine karşı fumigant etkileri araştırılmıştır. Denemeler $24 \pm 1{ }^{\circ} \mathrm{C}$ sıcaklık, $\% 65 \pm 5$ orantılı nem ve günlük 14 saatlik ışıklanma periyodunda yürütülmüştür. Denemeler, her biri $3 \mathrm{~cm}$ çaplı plastik hücrelere yerleştirilmiş 10'ar afit üzerinden ve üç tekerrürlü olarak yapılmıştır. Fumigant etki testlerinde, $A$. craccivora'ya uçucu yağların $30,45,60 \mu \mathrm{l} / \mathrm{I}$ hava dozları ve $M$. persicae'ya 10, 20, $30 \mu \mathrm{l} / \mathrm{l}$ hava dozları kullanılmıştır.

Uçucu yağların $A$. craccivora' ya karşı 24 saatlik uygulama süresinde en yüksek fumigant etkisi $30 \mu \mathrm{l} / \mathrm{l}$ ve $45 \mu \mathrm{l} / \mathrm{I}$ hava dozunda sırasıyla $\% 53.33$ ve $\% 70$ 'lik ölüm oranıyla rezene uçucu

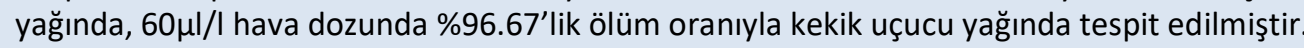
Uçucu yağların M. persicae'ya karşı 24 saatlik uygulama süresinde en yüksek fumigant etkisi

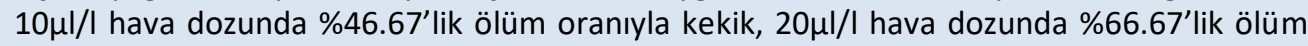
oranıyla lavanta, $30 \mu \mathrm{l} / \mathrm{I}$ hava dozunda \%86.67 ile anason ve lavanta uçucu yağında tespit edilmiştir. Özellikle düşük doz ve uygulama süresinde daha yüksek fumigant etki gösteren rezene uçucu yağının $A$. craccivora'ya, rezene ve kekik uçucu yağlarının ise $M$. persicae'ye karşı biyofumigant olma potansiyelinin olabileceği düşünülmektedir.

Anahtar Kelimeler: Bitkisel uçucu yağ, Fumigant etki, Myzus persicae, Aphis craccivora

\section{ABSTRACT}

Aphids are fast reproduction polyphage pests that feed with plant juice and develop resistance to pesticides in a short time. In this study, fumigant effects of thyme (Origanum onites L.), anise (Pimpinella anisum L.), fennel (Foeniculum vulgare Mill.) and lavender (Lavandula angustifolia Mill.) essential oils against adults of Aphis craccivora Koch and Myzus persicae Sulzer (Hemiptera: Aphididae) were investigated. The experiments were carried out at a $24 \pm 1{ }^{\circ} \mathrm{C}$ temperature, $65 \pm 5 \%$ relative humidity and $14 / 10 \mathrm{~L} / \mathrm{D}$ period. The experiments were done on 10 aphids placed in $3 \mathrm{~cm}$ diameter plastic cells and three replicated. In fumigant effect tests, 30, 45, $60 \mu \mathrm{l} / \mathrm{I}$ air doses of essential oils were used for $A$. craccivora and 10, 20, $30 \mu \mathrm{l} / \mathrm{l}$ air doses were used for M. persicae.

The highest fumigant effect of essential oil against $A$. craccivora at 24 hour exposure time was fennel essential oil with $53 \%$ and $70 \%$ mortality ratios at $30 \mu \mathrm{l} / \mathrm{I}$ air and $45 \mu \mathrm{l} / \mathrm{I}$ air doses respectively. Thyme essential oil was the most effective, with 24 hour exposure time and $96.67 \%$ mortality rate at $60 \mu \mathrm{l} / \mathrm{l}$ air dose.

The highest fumigant effect of essential oil against $M$. persicae in 24 hour exposure time was thyme essential oil with $47 \%$ mortality ratio at $10 \mu \mathrm{l} / \mathrm{I}$ air dose, lavender with $67 \%$ mortality ratio at $20 \mu \mathrm{l} / \mathrm{I}$ air dose, anise and lavander with $87 \%$ mortality ratio at $30 \mu \mathrm{l} / \mathrm{I}$ air dose. Fennel essential oil against A. craccivora fennel and thyme essential oils against M. persicae may have the potential to be biofumigant due to their higher fumigant effect at low dose and short application time.

Key Words: Plant essential oils, Fumigant, Aphis craccivora, Myzus persicae 


\section{Giriş}

Kaliteli ve gıda ihtiyacını karşılayacak miktarda ürün elde edilmesi amacıyla hastalık etmenleri, zararlılar ve yabancı otlara karşı geliştirilmiş olan mücadele yöntemlerinin başında kimyasal savaş gelmektedir (Türküsay ve Onoğur 1998). Kimyasal mücadelede kullanılan sentetik pestisitlerin çevreye verdiği zarar yanında, faydalı organizmalar üzerindeki yan etkileri ve bunun besin zinciri içerisinde negatif etkilerinin olduğu bilinmektedir. Ayrıca uzun süreli kullanımları sonucunda hedef organizmaların direnç kazanması ve insanlar dahil olmak üzere hedef dışı organizmalar için tehlikeli olması pestisit kullanımının diğer dezavantajlarıdır (Zhang ve ark. 2018).

Insanoğlu tarladaki ve depodaki ürünlerini böcek ve diğer zararlılardan korumak için yüzyıllardır değişik yöntemler kullanmıştır. Bu yöntemlerden biriside bitki ekstraktları ve uçucu yağlarının kullanımıdır. Bitkilerdeki biyokimyasal olaylardan sonra sentezlenen sekonder metabolitler değişik kategorilerde sınıflandırımakta olup bunların en önemlilerinin alkaloidler, glikozidler, fenoller, terpenoidler, taninler ve saponinlerdir. Bu maddelerden bazıları tarımda zararlılara karşı yüzyıllardan beri doğrudan veya dolaylı olarak kullanılmıştır (Shanker ve Solanki 2000). Apiaceae ve Lamiaceae familyasındaki aromatik bitkiler, tarih öncesi çağlardan günümüze kadar antiseptik ve tıbbi özellikleri ile de bilinmektedir (Hussain ve ark. 2011). Birçok aromatik bitki ve bunların esansiyel (uçucu) yağları eski çağlardan beri geleneksel tıpta (Lang ve Buchbauer, 2012) veya bitki ve hayvanların zararlı ve hastalıklarına karşı korunmak için kullanılmıştır (Bakkali ve ark. 2008).

Gelişmiş ülkelerde organik klorlu ve organik fosforlu insektisitlerin keşfinden önce tarımsal zararlılarla mücadelede bitkisel kökenli insektisitlerin kullanımı önemli bir yer tutmuştur (Isman 1997). Böcek öldürücü etkiye sahip bitkisel kökenli pyrethrum ithali, 1939 yılında Amerika'da 5400 ton iken, 1993 yılında bu miktar sadece 300 ton olmuştur (Genrty 1993). Sentetik insektisitlerin bitkisel kökenlilere göre daha etkili ve etki sürelerinin daha uzun olması, gelişmiş ülkelerde, sentetik insektisitlerin gelişen teknoloji sayesinde daha ucuz elde edilebilmesi bu durumun başlıca sebepleri olmuştur.

Günümüzde, uçucu yağlar ve bileşenlerinin, böceklerle mücadelede repellent ve böcek öldürücü etkilerini değerlendirmek için kapsamlı çalışmalar yapılmaktadır (Adorjan ve Buchbauer, 2010). Lavandula angustifolia Mil., Pimpinella anisum L. Origanum onites L. uçucu yağları veya bileşenlerini farklı çalışmalarda, Tyrophagus longior (Gervais) (Acarina; Acaridae)' a (Perrucci 1995), Thrips tabaci (Lindeman) (Thysanoptera: Thripidae)'ye (Koschier ve ark. 2002), Tetranychus urticae (Koch) (Acari: Tetranychidae)'ya (ElGengaihi ve ark. 1996) ve bazı ambar zararlılarına karşı (Saraç ve Tunç. 1995) kulanmış ve yüksek oranda insektisidal etki gösterdiğini belirlemişlerdir.

Dünyada son yıllarda doğal bileşiklerin (alkaloid, glikozid, uçucu yağ vs.) tarımsal alanlarda kullanım imkanlarının ortaya çıkması ve yaygınlaşması nedeniyle çevreye zarar veren tarım ilaçlarının tüketiminin önemli oranda azalacağı bildirilmektedir (Kan ve ark. 2005). Bitkisel kökenli insektisitlere ilgi bu nedenle, yeniden önem kazanmaya başlamış ve son yıllarda gelişmiş ülkelerde organik tarımla birlikte bu konudaki çalışmalar daha da hız kazanmıştır. Bu maddelerin doğada zaten bulunmaları nedeniyle doğaya ek toksik madde yayılmasının söz konusu olmaması, kısa zamanda dekompoze olarak toprak ve su kirliliklerine yol açmamaları, ürünler üzerinde insan sağlığını tehdit edecek uzun süreli kalıntılar oluşturmamaları, diğer canlılar için toksik olmaması nedenleri ile kullanımları tercih edilmektedir. Uçucu yağlar veya yağlara dayalı ürünler çoğunlukla memeliler, kuşlar ve balıklar için toksik değildir (Koul ve ark. 2008). Bugün 2000'den fazla bitkinin tarımda zararlı olan böceklere karşı çeşitli şekillerde etkili olduğu bilinmektedir (Öncüer 2000).

Türkiye'de yetişen yaklaşık 9000 bitki türünün birçoğu ülkemize has olup uzun yıllardır tıbbi ilaç hammaddesi olarak kullanılmaktadır (Baytop 1994). Geniş bir bitki örtüsüne sahip olan 
ülkemizde bitki zararlılarına karşı ekstrakt ve uçucu yağların kullanımı önemli bir potansiyel olarak görülmektedir. Bu araştırmada; çok sayıda bitki türünde beslenerek ve çeşitli virüs hastalıklarını taşıyarak zararlı olan iki önemli yaprak biti (Aphididae) türüne karşı bazı bitki uçucu yağlarının farklı dozlarının fumigant etkileri belirlenmiştir.

Yaprak bitleri, bitki özsuyunu emerek beslenen partenogenetik üremeleri ve nispeten kısa bir yaşam döngülerinin olması nedenleri ile hızlı çoğalan böceklerdir. Dünyada hemen her yerde rastlanmakla beraber, ılıman bölgelerde daha yaygın olarak bulunan yaprakbitlerinin (Zyla ve ark. 2017) halen 5000'den fazla türü bulunmaktadır (Blackman ve Eastop 2017).

Önemli bir zararlı olan şeftali yaprakbiti (Myzus persicae Sulz. Hemiptera: Aphididae), polifag bir tür olup, başta şeftali, kayısı, kiraz, erik, badem, turunçgiller, tütün, şekerpancarı, ıspanak, biber, patlıcan, domates, hıyar gibi birçok kültür bitkisi olmak üzere bazı orman, park ve süs bitkilerinde de ekonomik zarara neden olmaktadır (Uygun ve ark. 2013). Bitkisel insektisitler, yaprak bitlerine karşı bitki korumaya uygun bir alternatif olarak kabul edilmektedir (Isman ve Grieneisen 2014).

\section{Materyal ve Metot}

\section{Materyal}

\section{Bitkiler}

Çalışmada Origanum onites L. (kekik), Lavandula angustifolia Mill. (lavanta), Foeniculum vulgare Mill. (rezene) ve Pimpinella anisum L. (anason) bitkileri kullanılmıştır. Bitkilerin bağlı olduğu familyalar ve çalışmada kullanılan bitki kısımları Çizelge 1'de verilmiştir.

Çizelge 1. Uçucu Yağ Elde Edilen Bitkiler

Table 1. Essential Oil Derived Plants

\begin{tabular}{llll}
\hline $\begin{array}{l}\text { Adı } \\
\text { Name }\end{array}$ & $\begin{array}{l}\text { Bilimsel adı } \\
\text { Scientific name }\end{array}$ & $\begin{array}{l}\text { Familya } \\
\text { Family }\end{array}$ & $\begin{array}{l}\text { Kullanılan Kısım } \\
\text { Part Used }\end{array}$ \\
\hline $\begin{array}{l}\text { Kekik } \\
\text { Thyme }\end{array}$ & Origanum onites L. & Labiatae & Yeşil Aksam \\
Gaveen part \\
Lavender \\
$\begin{array}{l}\text { Anason } \\
\text { Anise }\end{array}$ & Lavandula angustifolia Mill. & Labiatae & Yeşil Aksam \\
Rezene & Pimpinella anisum L. & & Geen part \\
Fennel & Foeniculum vulgare Mill. & Umbelliferae & Fruit \\
\hline
\end{tabular}

\section{Böcekler}

Denemede Konya ilinden toplanan iki farklı yaprak biti türü kullanılmıştır. Kullanılan türler, toplandıkları yer ve konukçu bitkileri Çizelge 2'de verilmiştir.

Çizelge 2. Denemede kullanılan yaprakbiti türleri, toplandıkları yer ve konukçu bitkileri

Table 2. Aphid species used in the experiment, where they are collected and host plants

\begin{tabular}{lll}
\hline $\begin{array}{l}\text { Böcek Türü } \\
\text { Insect Species }\end{array}$ & $\begin{array}{l}\text { Toplandığı Yer ve Konukçu Bitkileri } \\
\text { Place and Host Plants }\end{array}$ & \\
\hline Myzus persicae & Şeftali (Çumra / Konya) & \\
(Hem.: Aphididae) & Peach & \\
& Akasya (Alaeddin & Keykubat \\
Aphis craccivora & Kampusü/ Konya) & \\
(Hem.: Aphididae) & Acacia & \\
&
\end{tabular}

\section{Metot}

\section{Bitkilerin Toplanması, Kurutulması ve Muhafazası}

Insektisit etkileri araştırılacak bitkilerden kekik ve anason Selçuk Üniversitesi Ziraat Fakültesi Tarla Bitkileri Bölümü'nden, rezene ve lavanta ise Selçuk Üniversitesi Çumra Meslek Yüksek Okulu'ndan temin edilmiştir. Toplanan bitkiler gölgede, havadar bir yerde sık sık çevrilerek kurutulmuş ve serin bir ortamda muhafaza edilmiştir.

\section{Böceklerin Yetiştirilmesi}

Denemede kullanılan Aphis craccivora Selçuk Üniversitesi Alaeddin Keykubat Kampüsündeki akasya ağaçlarından, Myzus persicae Çumra'dan şeftali ağaçlarından alınarak Selçuk Üniversitesi Ziraat Fakültesi Bitki Koruma Bölümü'nde teşhis edilmiştir. Teşhis edilen böcekler boyutları 
$45 \times 45 \times 45 \mathrm{~cm}$ olan plastik saksılar üzerine monte edilmiş yüksekliği $80 \mathrm{~cm}$ olan tül kafes içindeki bitkilere (Şekil 1) bulaştırılmıştır. Aphis craccivora için fasulye (Phaseolus vulgaris L.), Myzus persicae için hıyar (Cucumis sativus L.) bitkileri kullanılmış, bitkiler ve böcek kültürleri sera şartlarında geliştirilmiştir. Kültürlerin devamını sağlamak için böcekler, bitkilerin durumuna göre belirli aralıklarla taze bitkiler üzerine aktarılmıştır. Denemelerde 1- 2 günlük ergin bireyler kullanılmıştır.

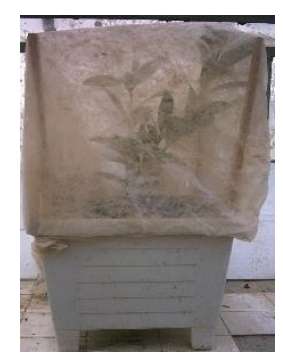

Şekil 1. Böceklerin yetiştirildiği düzenek

Figure 1. Insect rearing cage

\section{Uçucu Yağların Hazırlanması}

Kekik, anason, rezene ve lavanta uçucu yağlarını elde etmek için önceden kurutulmuş bitki materyali öğütülerek 100 gr tartılmış ve Clevenger düzeneğiyle üç saat su distilasyonuna tabi tutulmuştur. Elde edilen uçucu yağların suyu, sodyum sülfatla uzaklaştırılmış ve kullanılıncaya kadar koyu renkli, ağzı sıkıca kapatılmış şişeler içerisinde $+4{ }^{\circ}{ }^{\prime}$ 'deki buzdolabında muhafaza edilmiştir (Ceylan 1987).

\section{Uçucu Yağların Fumigant Etkilerinin Saptanması}

Uçucu yağların fumigant etkileri Aphis craccivora ve Myzus persicae'nın ergin bireylerine karşı test edilmiştir. Fumigant etki denemelerinde özel olarak hazırlanmış olan ve üzerinde üç adet 35 $\mathrm{mm}$ çapında ve $10 \mathrm{~mm}$ yüksekliğinde silindirik hücrenin bulunduğu $150 \mathrm{~mm}$ boyunda ve $50 \mathrm{~mm}$ eninde plastik plakalar (Şekil 2) kullanılmıştır. Test düzeneği içerisine önce muamele süresi boyunca yaprak disklerinin yeşil kalmasını sağlamak için 33 mm çapında nemli kurutma kağıdı daha sonra 33 $\mathrm{mm}$ çapında yaprak diskleri yerleştirilmiştir. Yaprak diskleri $A$. craccivora için fasulye bitkisinden, $M$. persicae için ise hıyar bitkisinden alınmıştır.

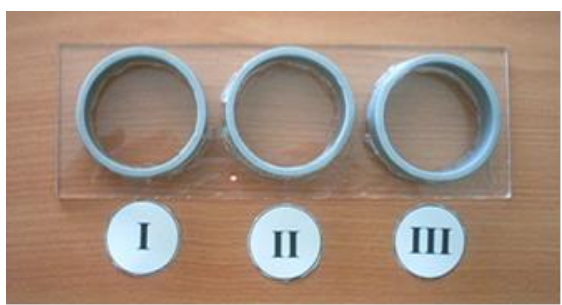

Şekil 2. Fümigant etki denemelerinde kullanılan 3 hücreli plaka

Figure 2. Three cell plate used in fumigant effect tests

Ön denemelerde farklı uçucu yağ dozları denenerek testlerde herbir yaprakbiti türü için uygulanacak uygun dozlar belirlenmiştir. Fumigasyon denemelerinde, uçucu yağların $A$. craccivora için 30, 45, $60 \mu \mathrm{l} / \mathrm{l}$ hava dozları, $M$. persicae için 10, 20, $30 \mu \mathrm{l} / \mathrm{l}$ hava dozları kullanılmıştır.

Uçucu yağ bileşenlerinin yaprak bitlerine karşı fumigant etkilerinin belirlenmesinde $24 \pm 1{ }^{\circ} \mathrm{C}$ sıcaklık ve $\% 65 \pm 5$ nispi neme ve günlük 14 saatlik ışıklanma periyoduna sahip iklim odası kullanılmıştır.

Yaprak biti erginleri, yetiştirildikleri bitkiler üzerinden ince uçlu (00 numara) samur fırça yardımıyla zedelenmeden alınarak içerisine nemli kurutma kağıdı ve yaprak diski yerleştirilmiş olan test düzeneğine aktarılmıştır. Her birinin bir tekerrür kabul edildiği plastik hücrelere 10 yaprakbiti ergini aktarılmış ve üzerine serigrafik bez gerilerek birer lastik bantla test düzeneğine sabitlenmiştir. Hazırlanan bu hücreler içindeki afitler bir litrelik cam kavanozlar içinde uçucu yağ bileşenlerinin buharlarına maruz bırakılmıştır (Şek. 3). Uçucu yağların her biri $10 \mu \mathrm{l}$ aseton ile seyreltildikten sonra Aphis craccivora için 30, 45, $60 \mu \mathrm{l} / \mathrm{l}$ hava, Myzus persicae için 10, 20, $30 \mu \mathrm{l} / \mathrm{I}$ hava dozuna karşılık gelecek şekilde kavanozların kapaklarının alt yüzüne yapıştırılan 30 × 30 mm boyutundaki kurutma kağıtlarına mikropipet yardımıyla emdirilerek uygulanmıştır. Kontrol dozu olarak da $10 \mu \mathrm{l} / \mathrm{l}$ hava dozunda aseton kullanılmıştır. Asetonun böceklerin tüm gelişme dönemlerine karşı buhar etkisinin bilinmesinden dolayı denemede kullanılan uçucu yağ dozlarının seyreltilmesinde ve kontrollerde kullanılan asetonun uçması için kapaklar bir süre (14- 22 sn) beklendikten sonra kapatılmıştır (Tunç ve 
Şahinkaya 1998). Denemelerde uçucu yağlar 24, 48 ve 72 saatlik sürelerde test edilmiştir. Belirtilen süreler sonunda kavanozlar açılarak stereo mikroskop altında sayımlar yapılmıştır. Sayımlarda her bir hücre açılıp içerisindeki yaprak bitlerine tek tek ince uçlu fırçayla dokunularak canlı olup olmadıkları kontrol edilmiş, herhangi bir hareket belirtisi göstermeyenler ölü, az da olsa hareket görülenler canlı olarak kabul edilmiştir (Erler 2000).

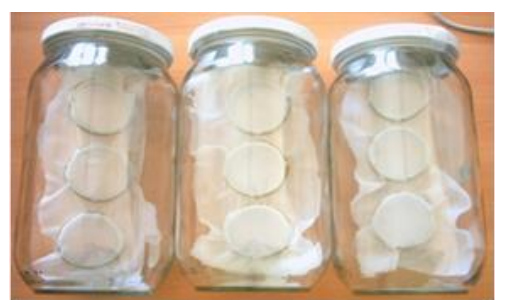

Şekil 3. Fumigasyon uygulamasında kullanılan düzenek Figure 3. Apparatus used in fumigation application

\section{Testlerden Elde Edilen Verilerin değerlendirilmesi}

Zararlı yaprak bitlerine karşı yapılan fümigant etki testlerinden elde edilen \% ölüm değerleri Arcsin transformasyonu yapıldıktan sonra istatistik Mstat paket programı kullanılarak varyans analizi yapılmış ortalamalar LSD testine tabi tutulmuştur.

\section{Araştırma Bulguları ve Tartışma}

Uçucu yağların Aphis craccivora erginlerine fümigant etkisi

Aphis craccivora'ya karşı fumigant etki testlerinden elde edilen sonuçlara göre; toksisitenin bitki uçucu yağına, uygulanan doz ve uygulama süresine bağlı olarak değiştiği görülmüştür (Çizelge 3).

Uçucu yağların $30 \mu l /$ I hava dozunda farklı uygulama süreleri değerlendirildiğinde 24 saatlik uygulama süresinde en yüksek etkinin $\% 53.33^{\prime}$ lük ölüm oranıyla rezene uçucu yağında, en düşük etkinin ise \%26.67'lik ölüm oranıyla anason uçucu yağında olduğu; 48 saatlik uygulama süresinde en yüksek etkinin \%86.67'lik ölüm oranıyla rezene uçucu yağında, en düşük etkinin ise $\% 63.33^{\prime}$ lük ölüm oranıyla lavanta uçucu yağında olduğu; en uzun uygulama süresi olan 72 saatte en yüksek etkinin \%100'lük ölüm oranıyla lavanta uçucu yağında, en düşük etkinin ise $\% 90.00$ 'lık ölüm oranıyla kekik uçucu yağında olduğu belirlenmiştir.

Uçucu yağların $45 \mu \mathrm{l} / \mathrm{I}$ hava dozunda 24 saatlik uygulama süresinde en yüksek etkinin $\% 70.00$ 'lik ölüm oranıyla rezene uçucu yağında, en düşük etkinin ise \%56.67'lik ölüm oranıyla lavanta uçucu yağında olduğu; 48 saatlik uygulama süresinde en yüksek etkinin \%100'lük ölüm oranıyla anason uçucu yağında, en düşük etkinin ise $\% 73.33^{\prime}$ lük ölüm oranıyla kekik uçucu yağında olduğu; 72 saatlik en uzun uygulama süresinde anason, rezene ve lavanta uçucu yağlarının \%100'lük ölüm oranı sağladığı, kekik bitkisinde ise bu oranın \%93.33 olduğu belirlenmiştir.

En yüksek doz olan $60 \mu \mathrm{l} / \mathrm{I}$ hava dozunda uçucu yağların 24 saatlik uygulama süresinde en yüksek etkinin \%96.67'lik ölüm oranıyla kekik uçucu yağında, en düşük etkinin ise \%83.33'lük ölüm oranıyla rezene uçucu yağında olduğu; 48 saatlik uygulama süresinde en yüksek etkinin \%100'lük ölüm oranıyla anason uçucu yağında, en düşük etkinin ise \%86.67'lik ölüm oranıyla kekik uçucu yağında olduğu tespit edilmiştir. $60 \mu \mathrm{l} / \mathrm{I}$ hava dozunda en uzun süre olan 72 saatlik uygulamada ise bütün bitki uçucu yağlarında \%100'lük ölüm oranı görülmüştür. Kekik uçucu yağının 30 ve $45 \mu \mathrm{l} / \mathrm{l}$ hava dozunda 48 saatlik uygulamaları hariç diğer uygulamaların hepsinde uygulanan uçucu yağların dozu ve uygulama süresi arttıkça etki artmıştır (Çizelge 3). 
Çizelge 3. Uçucu yağların Aphis craccivora erginlerine fumigant etkisi

Table 3. Fumigant effect of essential oils on Aphis craccivora adults

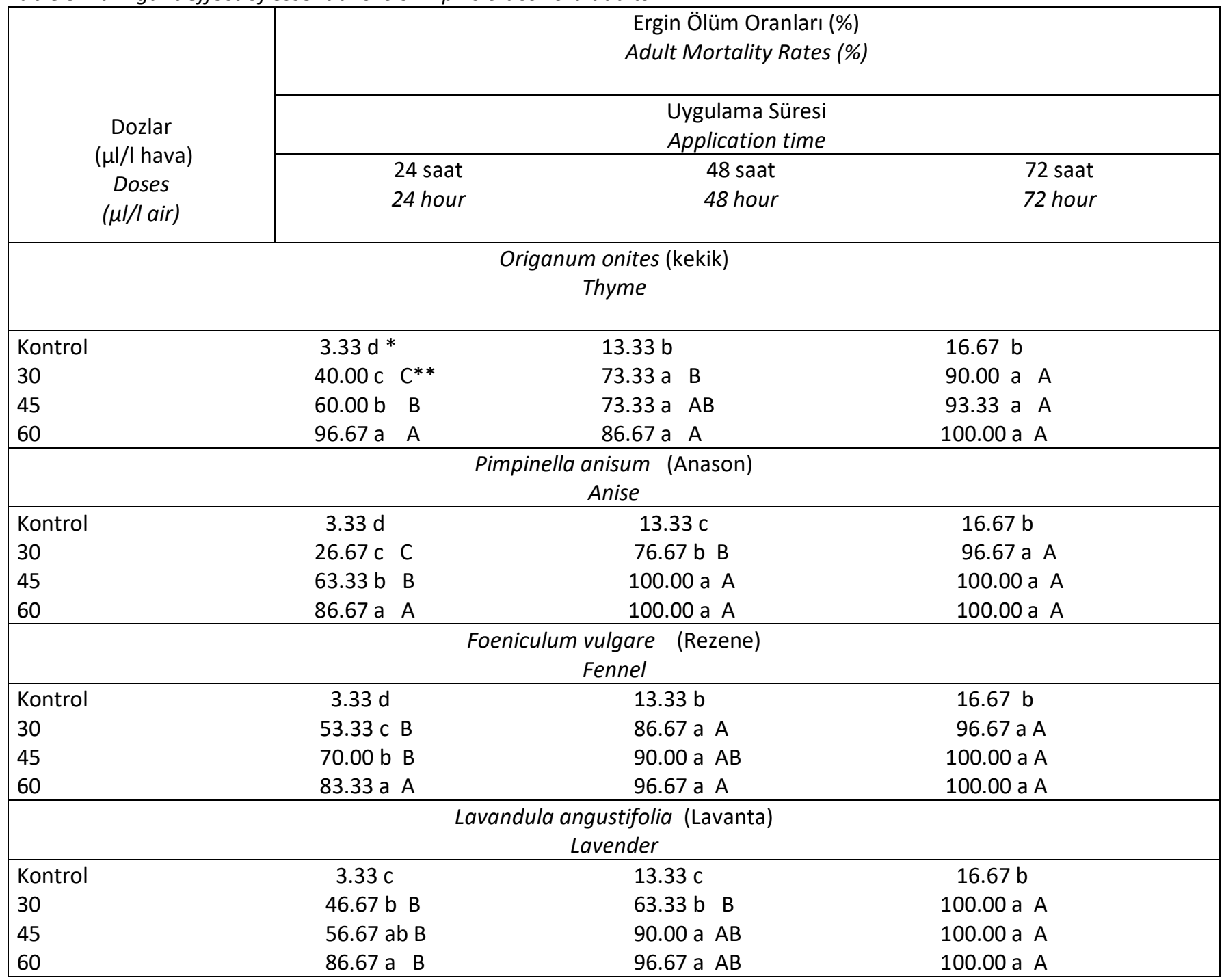

*Aynı sütundaki küçük harfler aynı ise ortalamalar arasındaki fark $(P>0.05)$ önemsizdir.

**Aynı satırdaki büyük harfler aynı ise ortalamalar arasındaki fark ( $P>0.05)$ önemsizdir.

* If the lower case letters in the same column are the same, the difference between the means $(P>0.05)$ is insignificant.

** If the capital letters on the same line are the same, the difference between the means $(P>0.05)$ is insignificant.

Uçucu yağların Myzus persicae erginlerine fümigant etkisi

Uçucu yağların $M$. persicae erginlerinde yol açtığı \% ölüm oranları Çizelge 4'te verilmiştir.

Uçucu yağların en düşük dozu olan $10 \mu \mathrm{l} / \mathrm{I}$ hava dozunda 24 saatlik uygulama süresinde en yüksek etkinin \%46.67lik ölüm oranıyla kekik uçucu yağında, en düşük etkinin ise \%36.67'lik ölüm oranıyla anason uçucu yağında olduğu; 48 saatlik uygulama süresinde en yüksek etkinin \%56.67'lik ölüm oranıyla rezene ve kekik uçucu yağında olduğu, lavanta ve anason uçucu yağlarının ise \%53.33'lük ölüm oranı meydana getirdiği ; 72 saatlik uygulama süresinde ise en yüksek etkinin \%96.67'lik ölüm oranıyla rezene uçucu yağında, en düşük etkinin ise \%86.67'lik ölüm oranıyla kekik ve anason uçucu yağında olduğu belirlenmiştir.

Uçucu yağların $20 \mu \mathrm{l} / \mathrm{I}$ hava dozunda 24 saatlik uygulama süresinde en yüksek etkinin \%66.67'lik ölüm oranıyla lavanta uçucu yağında, en düşük etkinin ise \%50.00'lik ölüm oranıyla rezene uçucu yağında olduğu; 48 saatlik uygulama süresinde en yüksek etkinin \%93.33'lük ölüm oranıyla anason uçucu yağında, en düşük etkinin ise \%73.33'lük ölüm oranıyla rezene uçucu yağında olduğu; 72 saatlik uygulama süresinde en yüksek etkinin \%100'lük ölüm oranıyla rezene ve lavanta uçucu yağında en düşük etkinin ise \%93.33'lük ölüm oranıyla kekik bitkisinde olduğu belirlenmiştir.

En yüksek doz olan $30 \mu \mathrm{l} / \mathrm{l}$ hava dozunda 24 saatlik uygulama süresinde en yüksek etkinin \%86.67'lik ölüm oranıyla anason ve lavanta uçucu 
yağında, en düşük etkinin ise \%73.33'lük ölüm oranıyla rezene uçucu yağında olduğu; 48 saatlik uygulama süresinde kekik, anason ve lavanta uçucu yağlarının \%100'lük etki gösterirken, rezene uçucu yağının \%86.67'lik ölüm oranı meydana getirdiği; Aynı dozda 72 saatlik uygulama süresinde ise bütün bitki uçucu yağlarında \%100'lük ölüm oranı görülmüştür. Uçucu yağların $M$. persicae'ya karşı fumigant etki testlerinde, uçucu yağların dozu ve uygulama süresi arttıkça etki artmıştır (Çizelge 4).

Çizelge 4. Uçucu yağların Myzus persicae erginlerine fumigant etkisi

Table 4. Fumigant effect of essential oils on Myzus persicae adults

\begin{tabular}{|c|c|c|c|}
\hline \multirow{3}{*}{$\begin{array}{c}\text { Dozlar } \\
\text { ( } \mu \mathrm{l} / \mathrm{l} \text { hava) } \\
\text { Doses } \\
\text { ( } \mu \mathrm{l} / \mathrm{l} \text { air })\end{array}$} & \multicolumn{3}{|c|}{$\begin{array}{l}\text { Ergin Ölüm Oranları(\%) } \\
\text { Adult mortality rates (\%) }\end{array}$} \\
\hline & \multicolumn{3}{|c|}{$\begin{array}{l}\text { Uygulama Süresi } \\
\text { Application time }\end{array}$} \\
\hline & $\begin{array}{l}24 \text { saat } \\
24 \text { hour }\end{array}$ & $\begin{array}{l}48 \text { saat } \\
48 \text { hour }\end{array}$ & $\begin{array}{l}72 \text { saat } \\
72 \text { hour }\end{array}$ \\
\hline \multicolumn{4}{|c|}{ Origanum onites (kekik) } \\
\hline Kontrol & $3.33 c^{*}$ & $10.00 \mathrm{c}$ & $20.00 \mathrm{~b}$ \\
\hline 10 & $46.67 \mathrm{~b} \quad \mathrm{~B}^{* *}$ & 56.67 b B & 86.67 a $A$ \\
\hline 20 & 63.33 ab B & 86.67 a $A B$ & 93.33 a $\mathrm{A}$ \\
\hline 30 & 80.00 a A & 100.00 a A & 100.00 a A \\
\hline \multicolumn{4}{|c|}{$\begin{array}{c}\text { Pimpinella anisum (Anason) } \\
\text { Anise }\end{array}$} \\
\hline Kontrol & $3.33 \mathrm{~d}$ & $10.00 \mathrm{c}$ & $20.00 \mathrm{c}$ \\
\hline 10 & 36.67 c C & $53.33 \mathrm{~b} \mathrm{~B}$ & 86.67 b A \\
\hline 20 & 63.33 b B & 93.33 a $\mathrm{A}$ & $96.67 \mathrm{ab} A$ \\
\hline 30 & 86.67 a A & 100.00 a A & 100.00 a A \\
\hline \multicolumn{4}{|c|}{$\begin{array}{c}\text { Foeniculum vulgare (Rezene) } \\
\text { Fennel }\end{array}$} \\
\hline Kontrol & $3.33 c$ & $10.00 \mathrm{c}$ & $20.00 \mathrm{~b}$ \\
\hline 10 & $43.33 \mathrm{~b} \mathrm{~B}$ & 56.67 b B & 96.67 a A \\
\hline 20 & $50.00 \mathrm{~b} \mathrm{C}$ & 73.33 ab B & 100.00 a $A$ \\
\hline 30 & 73.33 a A & 86.67 a A & 100.00 a $A$ \\
\hline \multicolumn{4}{|c|}{$\begin{array}{l}\text { Lavandula angustifolia (Lavanta) } \\
\text { Lavender }\end{array}$} \\
\hline Kontrol & $3.33 \mathrm{~d}$ & $10.00 \mathrm{~d}$ & $20.00 \mathrm{~b}$ \\
\hline 10 & 40.00 c B & 53.33 C B & 90.00 a A \\
\hline 20 & 66.67 b C & 86.67 b B & 100.00 a $A$ \\
\hline 30 & 86.67 a B & 100.00 a $A$ & 100.00 a A \\
\hline
\end{tabular}

${ }^{*}$ Aynı sütundaki küçük harfler aynı ise ortalamalar arasındaki fark $(P>0.05)$ önemsizdir.

**Aynı satırdaki büyük harfler aynı ise ortalamalar arasındaki fark $(P>0.05)$ önemsizdir.

* If the lower case letters in the same column are the same, the difference between the means $(P>0.05)$ is insignificant.

** If the capital letters on the same line are the same, the difference between the means $(P>0.05)$ is insignificant.

Erler (2000) Aphis gossypii Glover (Hemiptera: Aphididae) erginlerine karşı kekik uçucu yağının etken maddelerinden olan carvacrol ve thymol'ü ve rezene uçucu yağının etken maddelerinden olan anethole'ü fumigasyon şeklinde denemiş, süre arttıkça (24, 48, 96 saatlik uygulama sürelerinde) ölüm oranının arttığını belirlemiştir. Araştırıcı aynı çalışmada artan uygulama dozlarının da (0.2;0.4; 0.8 ve $1.7 \mathrm{mg} /$ It hava) ölüm oranını arttırdığını ve artan sürenin dozdan daha önemli olduğunu bildirmiştir. Araştırma bulgularımız da her iki yaprakbiti türü ile yapılan deneme sonuçları, araştırıcının sonuçları ile benzerlik göstermekte olup doz ve gün arttıkça fumigant etkide artış görülmüştür.

Tokat ilinde yapılan bir çalışmada Labiatae (Lamiaceae) türleri (Origanum onites L.,Origanum vulgare L., Origanum majorana L. , Thymbra spicata L. ve Thymus vulgaris L.) 'nin uçucu yağlarının dört farklı dozu $(\% 0,5, \% 1, \% 2, \% 4 \mu \mathrm{l} / \mathrm{l})$ 'nun íki noktalı kırmızı örümceğe (Tetranychus urticae Koch) karşı repellent etkileri araştırımıştır. Ele alınan beş kekik türü içinde repellent etkisi en yüksek olan türün $O$. onites olduğu tespit edilmiştir. (Yeşilayer A., Aslan H.N. 2018) 
Perrucci (1995) iki farklı lavanta bitkisinin (Lavandula angustifolia Mill. ve Lavandula stoechas L.) uçucu yağları ve bunların ana bileşeni olan linalyl acetate'ın, ambar zararlısı bir akar olan Tyrophagus longior (Gervais)'a karşı fümigant toksisitesini test etmiş, en yüksek dozlarda 2 lavanta bitkisi uçucu yağlarının \%100 ölüme neden olduğunu tespit etmiştir.

Saraç ve Tunç (1995) Pimpinella anisum L. uçucu yağının fümigant etkisini bazı ambar zararlılarına karşı 108-135 $\mu \mathrm{l} / 1$ litre hava doz aralığında denemiş ve anason uçucu yağının 24 ile 144 saat arasında yüksek toksisite etkisini (\%95) belirlemişlerdir. Yaptığımız çalışmada araştırmacıların elde ettiği sonuçlara daha kısa sürede ulaşmıştır. Lavanta bitkisi uçucu yağının \%1'lik konsantrasyonunu Thrips tabaci (Lindeman)'ye karşı kullanan Koschier ve ark. (2002) bu uçucu yağın zararlıya karşı önemli derecede insektisidal etki gösterdiğini belirlemişlerdir.

El-Gengaihi ve ark. (1996) kekik uçucu yağının ve ana bileşenlerinden thymol'ün Tetranychus urticae (Koch)'ya karşı biyolojik aktivitesini test etmişlerdir. Her iki maddenin de toksisite testlerinde yüksek konsantrasyonlarda \%100 ölüm meydana getirdiğini, fakat düşük konsantrasyonlarda thymol'ün kekik uçucu yağından daha etkili olduğunu saptamışlardır.

Isman (2000) laboratuar şartlarında Myzus persica (Sulz.)e'nın nimflerine karşı kekik uçucu yağının kontak etkisini test etmiş, testler sonucunda beslenen afitin sayısının 48 saatte 24 saate göre $\% 50$ 'den $\% 25^{\prime}$ e düştüğünü, ölen afitlerin oranının da \%22'den \%60'a çıktığını tespit etmiştir. Bu sonuçlar araştırma bulgularımızla paralellik göstermektedir.

Ikbal ve Pavela (2019) fümigasyon testlerinde kullanılan 16 bitki türünün uçucu yağlarının $2 \mu \mathrm{l}$ dozunda uygulandığında \%90'dan daha fazla yaprak biti ölümüne neden olduğunu tespit etmişlerdir. $\mathrm{Bu}$ bitkilerden beş tanesinden (Foeniculum vulgare (Mill.), Mentha piperita L., M. Pulegium L., Ocimum basilicum L. ve Pimpinella anisum L.) elde edilen uçucu yağların hem değme hem de fumigasyon testlerinde mükemmel etkinlik gösterdiğini ve bu nedenle botanik afidisidlerin gelişimi için optimum aktif madde kaynağı olabileceğini belirtmişlerdir.

Alghamdi (2018) yaptığı araştırmada dört bitki (Moringa oleifera L., Eruca sativa L., Raphanus sativus L., Allium sativum L.) uçucu yağının değme etkisini, gül yaprak biti (Macrosiphum rosae L.) ve bakla yaprak bitine (Aphis fabae Scopoli (Hemiptera: Aphididae) karşı \%1, \%2 ve \%4 konsantrasyonlarında denemiş ve $12,24,48$ ve 72 saat maruz bırakma süresinden sonra, ölüm oranlarının farklı deneme sürelerinde, uçucu yağ konsantrasyonlarının artmasıyla arttığını ortaya koymuştur. Uçucu yağ testlerinde roka yağı, $M$. rosae'ya karşı tüm konsantrasyonlarda \%97.5'e ulaşan ölüm oranıyla en yüksek değeri vermiş, bunu sırasıyla sarımsak yağı (\%80.6), turp yağı (\%69.2) ve moringa yağı (\%63.3) izlemiştir. A. fabae için de benzer sonuçlar alınmıştır. Çalışmada bu tür uçucu yağların iki yaprak biti türüne karşı kullanılmasının olası olduğu değerlendirilmiştir.Işık ve Görür (2009) yedi bitki uçucu yağının değme etkisini (Juniperus excelsa Bieb., Juniperus oxycedrus L., Foeniculum vulgare Mill., Pimpinella anisum L., Rosmarinus officinalis L., Juglans regia L. ve Laurus nobilis L.) afisidal aktivitelerinin lahana yaprak bitine (Brevicoryne brassicae Hemiptera: Aphididae) karşı etkilerini laboratuvar koşullarında test etmişler ve bu uçucu yağların, lahana yaprak bitinin üreme potansiyelini önemli ölçüde azalttığını ve yüksek oranda ölüme yol açtığını tespit etmişlerdir.

Araştırma sonuçlarımıza göre özellikle düşük doz ve uygulama süresinde daha yüksek fumigant etki gösteren rezene ve kekik uçucu yağlarının biyofumigant potansiyeline sahip oldukları sonucuna varılmıştır.

\section{Ekler}

Bu makale Orhan Mülayim'in yüksek lisans çalışmasından alınmıştır. 5-8 Eylül 2016 yılında Konya'da yapılan Bitki Koruma Kongresinde özet olarak yayınlanmıştır.

Çıkar Çatışması Beyanı: Makale yazarları aralarında herhangi bir çıkar çatışması olmadığını beyan ederler. 


\section{Kaynaklar}

Adorjan B., \& Buchbauer G. (2010). Antimicrobial agents from plants: antibacterial activity of plant volatile oils. Flavour Fragr. J. 25:407-426.

Alghamdi A.S. (2018). Insecticidal effect of four plant essential oils against two aphid species under laboratory conditions. Journal of Applied Biology \& Biotechnology Vol. 6(2), 27-30, Mar-Apr,2018 DOI:10.7324/JABB.2018.60205.

Bakkali F., Averbeck S., Averbeck D., \& Idoamar M., (2008). Biological effects of essential oils- a review. Food and chemical Toxicology. 46(2):446-475.

Baytop, T. (1994). Türkiye'de Tıbbi ve Kokulu Bitkilerin Kullanılışına Tarihsel Bir Bakış. Tıbbi ve Aromatik Bitkiler Bülteni, Sayı 10, s.24-27.

Blackman R.K., \& Eastop V.F. (2017) Taxonomic issues. In: van Emden $\mathrm{H}$, Harrington $\mathrm{R}$ (eds) Aphids as crop pests, 2nd edn. CABI Publishing, Wallingford, 1-36

Ceylan, A., (1987). Tıbbi Bitkiler 2. Ege Üniversitesi Ziraat Fakültesi Yayınları. No:481. İzmir.

El-Gengaihi, S.E., Amer, S.A.A and Mohamed, S.M. (1996). Biological Activity Of Thyme Oil And Thymol Against Tetranychus urticae Koch. Anz. Schadlingskde., Pflanzenschutz, Umweltschutz, 69: 157-159.

Erler, F. (2000). Bitki kökenli Bileşiklerin Böcek ve Akarlarla Mücadelede Kullanılma Potansiyeli Üzerinde Araştırmalar. Akdeniz Üniversitesi Fen Bilimleri Enstitüsü Bitki Koruma Anabilim Dalı Doktora Tezi. Antalya.

Genrty, A. H. (1993). Tropical forest diversity and the potential for new medicinal plants. Pages 13-24 in Human Medicinal Agents from Plants. Eds A.D. Kinghorn and M.F. Balandrin, ACS Symp. Ser.543.

Hussain A. I., Anwar F., İqbal T., \& Bhatti i. A. (2011). Antioxidant attributes of four Lamiaceae Essential oils. Pak. J. Bot. 43(2):1315-1321.

ikbal C., \& Pavela R. (2019). Essential oils as active ingredients of botanical insecticides against aphids. Journal of Pest ScienceJune 2019, Volume 92, $\underline{3}$, 971-986.

Isman, M. B., (1997). Neem And Other Botanical Insecticides: Barriers To Commercialization. Phytoparasitica, 25(4): 339- 344.

Isman, B. M. (2000). Plant essential oils for pest and disease management. Faculty of Agricultural Sciences, University of British Columbia-Canada.

Isman M.B., \& Grlenelsen M. L. (2014). Botanical insecticide research: many publications, limited useful data. Trends Plant Sci 19:140-145.

Işık M., \& Görür G., (2009). “Aphidicidial activity of seven essential oils against the cabbage aphid, Brevicoryne brassicae L. (Hemiptera: Aphididae)", Mun. Ent. Zool., vol. 4, no. 2, pp. 424-431.

Kan, Y., Arslan, N., Altun, L. ve Kartal,M. (2005).Türkiye'de Tıbbi ve Aromatik Bitkilerin Kültürünün Ekonomik Önemi.15. BiHAT Toplantısı Bildirisi (5- 7 Ekim 2005), Antalya.

Koschier, E.H., Sedy,K.A. and Novak, J. (2002). Influence of Plant Volatiles on Feeding Damage Caused by the Onion Thrips Thrips tabaci. Crop Protection, Volume 21, (5), 419-425.

Koul O., Walla S., \& Dhaliwal G.S. (2008). Essential Oils as Green Pesticides: Potential and Constraints. Biopestic. Int. 4(1):63-84.

Lang G., \& Buchbauer G. (2012). A review on recent research results (2008-2010) on essential oils as antimicrobials and antifungals. A review. Flavour Fragr. J. 27:13-39.

Öncüer, C. (2000). Tarımsal Zararlılarla Savaş Yöntem ve ilaçları. Adnan Menderes Üniversitesi Yayınları No:13, 4. Baskı, Aydın, $333 \mathrm{s.}$

Perrucci, S. (1995). Acaricidal activity of some essential oils and their constituents against Tyrophagus longior, a mite of stored food. J. Food Pr., 58(5):560-563.

Saraç, A. and Tunç, í. (1995). Residual toxicity and repellency of essential oils to stored product Insects. Z. Pflkrankh. Pflschutz., 102 (4): 429-434.

Shanker, C. and K.R. Solanki. (2000). Botanical insecticides: A Historical Perspective. India, Asian Agrihistory 4(2): 21- 30.

Tunç, i. and Şahinkaya Ş., (1998). Sensitivity of two greenhouse pests to vapours of essential oils. Ent. Exp. Et Appl., 86: 183-187.

Türküsay, H. and Onoğur, E. (1998). Bazı bitki ekstraktlarının In vitro antifungal etkileri üzerine araştırmalar. Turkish Journal of Agriculture and Foresty. 22: 267271.

Uygun, N., Ulusoy, M. R., \& Karaca, İ., (2013). Meyve ve bağ zararlıları. Çukurova Üniversitesi, Ziraat Fakültesi Ders Kitabı. Genel Yayın No:252, Yayın No: A-81, Adana, $344 s$.

Yeşilayer A., Aslan H.N. (2018). Bazı kekik türlerinden elde edilen uçucu yağların iki Noktalı kırmızı örümcek (Tetranychus urticae Koch, Acari: Tetranychidae) üzerine repellant etkisi. ÇOMÜ Zir. Fak. Derg. (COMU J. Agric. Fac.) 2018: 6 13- 20 ISSN: 2147-8384 / eISSN: 2564-6826.

Zhang Q., LI Z., Chang C.H., Lou J.L., Zhao M.R., \& Lu C. (2018). Potential human exposures to eonicotinoid insecticides: a review. Environ Pollut 236:71-81.

Zyla D, Homan A., Weglerek P. (2017). Polyphyly of the extinct family Oviparosiphidae and its implications for inferring aphid evolution (Hemiptera, Sternorrhyncha). PLOS ONE 12:e0174791. https ://doi. org/10.1371/journ al.pone.01747 91. 